\section{EVALUASI PELAKSANAAN KOMUNIKASI EFEKTIF “STATUS PRESENT” PADA HANDOVER EMERGENCY DI RSU HAJI SURABAYA}

\section{Evaluation of Effective Communication of "Present Status" in Emergency Handover in Haji General Hospital Surabaya}

\section{Muhammad Hendri Haryono*1, Dwi Ernawati2}

1. Rumah Sakit Umum Haji Surabaya

2. STIKES Hang Tuah Surabaya

\section{Riwayat artikel}

Diajukan: 5 Agustus 2019

Diterima: 28 Maret 2020

\section{Penulis Korespondensi: \\ - M Hendri Haryono \\ - Rumah Sakit Haji \\ Surabaya \\ hendrickerss@gmail.com}

\section{Kata Kunci:}

Komunkasi efektif, SBAR, Handover emergency

\begin{abstract}
Abstrak
Pendahuluan: Pelaksanaan pengisian komunikasi efektif SBAR pada handover emergency harus sesuai dengan standard. Dari hasil evaluasi dokumen rekam medis menunjukkan bahwa indikator instrumen pada status present belum terdokumentasi dengan baik. Tujuan dari penelitian ini adalah menyusun pengembangan instrumen komunikasi efektif SBAR pada handover emergency

Desain penelitian menggunakan deskriptif. Sampel penelitian ini adalah 150 dokumen rekam medis dan 15 partisipan dalam proses FGD. Partisipan dipilih menggunakan purposive sampling. Analisa data menggunakan analisis deskriptif.

Instrumen komunikasi efektif (status present) pada handover emergency banyak yang tidak sesuai standar, Penerapan pengisian status present pada handover emergency di ruang RSU Haji Surabaya menunjukkan bahwa seluruh responden memiliki kemampuan yang cukup dalam mengisi format status present

Komunikasi efektif status present pada penelitian ini adalah instrumen handover yang mencakup seluruh informasi dan perencanaan serta memuat kondisi pasien terkini yang dibutuhkan oleh perawat IGD. Instrumen komunikasi efektif SBAR ini dilakukan untuk meningkatkan mutu pelayanan keperawatan dan mencegah terjadinya kejadian tidak diharapkan pada pasien.
\end{abstract}

\section{Abstract}

Introduction The implementation of filling SBAR effective communication on emergency handovers must be in accordance with the standards. From the evaluation results of medical record documents show that the instrument indicators on the present status have not been well documented. The purpose of this study is to develop the development of SBAR effective communication instruments in emergency handovers

The study design uses descriptive. The sample of this study was 150 medical record documents and 15 participants in the FGD process. Participants were selected using purposive sampling. Data analysis uses descriptive analysis.

Many effective communication instruments (status present) in emergency handovers do not conform to the standard. The application offilling in the present status in emergency handovers in the Haji Hospital Surabaya shows that all respondents have sufficient ability to fill in the present status format.

Effective communication of the present status in this study is a handover instrument that includes all information and planning and includes the latest patient conditions needed by emergency nurses. The SBAR effective communication instrument is carried out to improve the quality of nursing services and prevent the occurrence of unexpected events in patients. 
yang paling penting dalam sebuah layanan asuhan keperawatan, prinsip dasar dari suatu layanan pasien dan merupakan bagian komponen kritis dari manajemen mutu keselamatan dalam layanan kesehatan. Komunikasi yang efektif di kalangan profesional kesehatan adalah kunci untuk memastikan perawatan yang berkualitas dalam praktek klinis. Salah satu bentuk untuk memastikan perawatan yang berkualitas dalam praktek klinis adalah adanya handover (serah terima) yang telah didefinisikan sebagai pengalihan tanggung jawab klinis, telah menerima peningkatan perhatian internasional. Serah terima klinis telah didefinisikan sebagai pengalihan tanggung internasional dan / atau akuntabilitas untuk perawatan pasien dari satu penyedia atau tim penyedia lain serta serah terima keperawatan (Bakon \& Millichamp, 2017)

Dalam pelaksanaannya proses komunikasi yang terjadi di bidang kesehatan sering tidak efektif hanya terbatas pada mengirim atau menerima telepon dan meninggalkan pesan antara petugas kesehatan. Dan akibatnya banyak pesan yang tidak tersampaikan dengan maksimal. Mengembangkan hubungan kerja kolaboratif dan komunikatif antara petugas adalah kunci keberhasilan pelayanan yang berfokus pada pasien. Komunikasi antara petugas kesehatan (Handover) merupakan komunikasi yang dilakukan secara akurat, lengkap, dimengerti, tidak duplikasi dan tepat kepada penerima informasi untuk mengurangi kesalahan dan meningkatkan keselamatan pasien (Moy et al., 2014). Proses handover pasien merupakan suatu interaksi yang kompleks antara para tenaga medis yang nantinya akan secara langsung mempengaruhi perawatan pasien. Keefektifan dan kelengkapan dari proses handover ini akan membawa keberlangsungan perawatan pasien selanjutnya (Bakon and Millichamp. 2017).

Bakon and Millichamp (2017) juga menjelaskan bahwa handover sebagai bukti dari sebuah tanggung jawab perawatan pasien untuk keberlangsungan kesehatan pasien selanjutnya. Ketidaklengkapan data saat handover akan menyebabkan kerugian, diantaranya adanya kesalahan pengobatan, perawatan yang tidak tepat, atau keterlambatan pengobatan pasien. Kegagalan dalam berkomunikasi merupakan salah satu akar masalah yang paling sering menyebabkan insiden keselamatan pasien. Dengan adanya nilai dan keyakinan yang berkaitan dengan masalah komunikasi yang optimal, maka setiap perawat akan mengetahui apa yang seharusnya diakukan dalam penerapan mutu layanan keperawatan. Dengan demikian, perilaku tersebut pada akhirnya menjadi suatu budaya yang tertanam dalam setiap perawat berupa perilaku budaya keselamatan pasien (Defenbaugh and Chikotas, 2016). Berdasarkan latar belakang yang dijelaskan tersebut maka peneliti tertarik untuk melakukan penelitian tentang "Evaluasi pelaksanaan Komunikasi Efektif Situation, Background, Assesment, Recomendation di RSU Haji Surabaya"

\section{METODE}

Desain penelitian menggunakan analisa data deskriptif, dengan jumlah sampel 150 dokumen rekam medik dan kegiatan FGD 15 responden dengan menggunakan purposive sampling.

\section{HASIL}

Pengambilan data dilakukan pada $02 \mathrm{Mei}$ - 02 Juni 2019, dan ditetapkan 15 responden pada saat FGD dan 30 responden saat pelaksanaan handover emergency dengan intrumen situasion, background, assesment, recomendation (SBAR) ada bagian hasil diuraikan data tentang gambaran umum tempat penelitian, data umum dan data khusus.

\section{PEMBAHASAN}

Evaluasi dokumen SBAR di ruang IGD RSU Haji Surabaya dinilai menggunakan lembar observasi pada tabel 5.1. Indikator pertanyaan pada handover emergency dengan status present dari ruang IGD ke ruang rawat inap yang sedang dan sudah di terapkan di RSU Haji Surabaya, belum mengacu kepada Standar Nasional Akreditasi Rumah Sakit. Pengisian lembar status present pada Handover Emergency juga belum sesuai standar karena belum terdapat SPO dan panduan pengisian yang jelas bagi perawat sehingga pelaksanaan 
komunikasi efektif SBAR pada Handover

Emergency belum optimal.

Tabel 1. Hasil Evaluasi Status Present yang Digunakan di RSU Haji Surabaya

\begin{tabular}{|c|c|c|c|c|}
\hline No & $\begin{array}{l}\text { Karakteristik Instrumen } \\
\text { Komunikasi Efektif } \\
\text { (Status Present) }\end{array}$ & Data & $\Sigma$ & $(\%)$ \\
\hline \multicolumn{5}{|c|}{ Sebelum Transfer } \\
\hline \multirow[t]{5}{*}{1} & \multirow[t]{5}{*}{ Identitas } & Nomer Rekam Medik & 83 & 55.3 \\
\hline & & Nama & 83 & 55.3 \\
\hline & & Tanggal Lahir & 83 & 55.3 \\
\hline & & Umur & 83 & 55.3 \\
\hline & & Alamat & 83 & 55.3 \\
\hline \multirow[t]{2}{*}{2} & \multirow[t]{2}{*}{ Keadaan Umum } & GCS & 112 & 74.6 \\
\hline & & Keluhan Utama & 112 & 74.6 \\
\hline \multirow[t]{5}{*}{3} & \multirow[t]{5}{*}{ Tanda-Tanda Vital } & Tekanan darah (TD) & 147 & 98.0 \\
\hline & & Nadi & 144 & 96.0 \\
\hline & & Pernafasan (RR) & 148 & 98.6 \\
\hline & & Suhu & 147 & 98.0 \\
\hline & & $\begin{array}{l}\text { Saturasi oksigen } \\
\text { (Spo2) }\end{array}$ & 58 & 38.6 \\
\hline 4 & Pemeriksaan Fisik & Keadaan umum & 0 & 0 \\
\hline \multirow[t]{5}{*}{5} & \multirow[t]{5}{*}{ Catatan Penting } & Injeksi & 50 & 33.3 \\
\hline & & Laboratorium & 143 & 95.3 \\
\hline & & Radiologi & 142 & 94,6 \\
\hline & & ECG & 76 & 50.6 \\
\hline & & Konsul & 52 & 34.6 \\
\hline \multirow[t]{2}{*}{6} & \multirow[t]{2}{*}{ Identitas Petugas } & Nama & 148 & 98.6 \\
\hline & & Tanda tangan perawat & 148 & 98.6 \\
\hline \multicolumn{5}{|c|}{ Saat Transfer } \\
\hline \multirow[t]{5}{*}{1} & \multirow[t]{5}{*}{ Identitas } & Nomer Rekam Medik & 83 & 55.3 \\
\hline & & Nama & 83 & 55.3 \\
\hline & & Tanggal Lahir & 83 & 55.3 \\
\hline & & Umur & 83 & 55.3 \\
\hline & & Alamat & 83 & 55.3 \\
\hline \multirow[t]{2}{*}{2} & \multirow[t]{2}{*}{ Keadaan Umum } & GCS & 133 & 88.6 \\
\hline & & Keluhan Utama & 133 & 88.6 \\
\hline \multirow[t]{5}{*}{3} & \multirow[t]{5}{*}{ Tanda-Tanda Vital } & Tekanan darah (TD) & 117 & 78.0 \\
\hline & & Nadi & 136 & 90.6 \\
\hline & & Pernafasan (RR) & 136 & 90.6 \\
\hline & & Suhu & 100 & 66.6 \\
\hline & & $\begin{array}{l}\text { Saturasi oksigen } \\
\text { (Spo2) }\end{array}$ & 29 & 19.3 \\
\hline 4 & Pemeriksaan Fisik & Keadaan Umum & 0 & 0 \\
\hline 5 & Catatan Penting & EWS & 78 & 52.0 \\
\hline
\end{tabular}




\begin{tabular}{lllll}
\hline No & $\begin{array}{l}\text { Karakteristik Instrumen } \\
\text { Komunikasi Efektif } \\
\text { (Status Present) }\end{array}$ & Data & $\Sigma$ & $(\%)$ \\
\hline & & Skala Transfer & 96 & 64.0 \\
\cline { 2 - 5 } & Riwayat jatuh & 59 & 39.3 \\
\hline 6 & Identitas Petugas & Nama & 145 & 96.6 \\
\hline & Tanda tangan perawat & 147 & 98.0 \\
\hline
\end{tabular}

Saat di Ruangan

\begin{tabular}{|c|c|c|c|c|}
\hline \multirow[t]{5}{*}{1} & Identitas & Nomer Rekam Medik & 83 & 53.3 \\
\hline & & Nama & 83 & 53.3 \\
\hline & & Tanggal Lahir & 83 & 53.3 \\
\hline & & Umur & 83 & 53.3 \\
\hline & & Alamat & 83 & 53.3 \\
\hline \multirow[t]{2}{*}{2} & Keadaan Umum & GCS & 149 & 99.3 \\
\hline & & Keluhan Utama & 148 & 98.6 \\
\hline \multirow[t]{5}{*}{3} & Tanda-Tanda Vital & Tekanan darah (TD) & 127 & 84.6 \\
\hline & & Nadi & 136 & 90.6 \\
\hline & & Pernafasan (RR) & 113 & 75.3 \\
\hline & & Suhu & 113 & 75.3 \\
\hline & & $\begin{array}{l}\text { Saturasi oksigen } \\
\text { (Spo2) }\end{array}$ & 89 & 59.3 \\
\hline 4 & Pemeriksaan Fisik & Keadaan Umum & 0 & 0 \\
\hline \multirow[t]{5}{*}{5} & Catatan Penting & Laboratorium & 125 & 83.3 \\
\hline & & ECG & 74 & 49.3 \\
\hline & & Radiologi & 38 & 25.3 \\
\hline & & Status & 4 & 2.6 \\
\hline & & SEP & 4 & 2.6 \\
\hline \multirow[t]{2}{*}{6} & Identitas Petugas & Nama & 143 & 95.3 \\
\hline & & Tanda tangan perawat & 148 & 95.3 \\
\hline
\end{tabular}

Tabel 2. Isu strategis dari hasil evaluasi handover emergency status present

\begin{tabular}{|c|c|c|}
\hline Variabel & Data & Issu Strategis \\
\hline Situasion & $\begin{array}{l}\text { 1. Pada identitas pasien, masih banyak form } \\
\text { handover yang tidak diberi label identitas pasien } \\
(60.6 \%) \text {. } \\
\text { 2. Pada aspek situasion kurang menggambarkan } \\
\text { kondisi pasien terkini (kurang jelas dan kurang } \\
\text { terperinci) } \\
\text { 3. Tidak memuat diagnosa medis dan diagnosa } \\
\text { keperawatan }\end{array}$ & $\begin{array}{l}\text { Pemahaman perawat } \\
\text { tentang pentingnya } \\
\text { memberikan label } \\
\text { identitas masih kurang }\end{array}$ \\
\hline Background & $\begin{array}{l}\text { 1. Pada background sebagian besar sudah diisi } \\
\text { oleh perawat IGD }(98.6 \%) \text {. } \\
\text { 2. Pada aspek background pada format ini hanya } \\
\text { memuat tanda-tanda vital saja } \\
\text { 3. Tidak ada pengkajian mengenai riwayat } \\
\text { penyakit sekarang, penyakit sebelumnya, } \\
\text { penyakit keluarga } \\
\text { 4. Tidak ada riwayat alergi, penyakit menuar }\end{array}$ & $\begin{array}{l}\text { Adanya duplikasi } \\
\text { pencatatan pada lembar } \\
\text { status present (saat } \\
\text { transfer dan selama } \\
\text { transfer) }\end{array}$ \\
\hline Assesment & $\begin{array}{l}\text { 1. Assesment sebagian besar form handover yang } \\
\text { tidak diisi oleh perawat }(11 \%) \text {. }\end{array}$ & $\begin{array}{l}\text { Instrumen komunikasi } \\
\text { efektif berupa status }\end{array}$ \\
\hline
\end{tabular}




\begin{tabular}{|c|c|c|}
\hline Variabel & Data & Issu Strategis \\
\hline & $\begin{array}{l}\text { 2. Assesment dalam format banyak yang tidak diisi, } \\
\text { karena tiap-tiap perawat mempunyai persepsi } \\
\text { yang berbeda mengenai tehnis pelaksanaan } \\
\text { pengisian format tersebut } \\
\text { 3. Tanda-tanda vital yang seharusnya ada dalam } \\
\text { aspek ini, namun sudah tertuang dalam aspek } \\
\text { background diatas } \\
\text { 4. Belum ada SOP (standart operasional } \\
\text { prosedure) mengenai tehnis pelaksanaan } \\
\text { pengisian format handover }\end{array}$ & $\begin{array}{l}\text { present belum sesuai } \\
\text { dengan standar }\end{array}$ \\
\hline Rekomendation & $\begin{array}{l}\text { 1. Recomendation ini juga banyak yang tidak diisi } \\
(54.3 \%) \text {, karena tiap-tiap perawat mempunyai } \\
\text { persepsi yang berbeda mengenai tehnis } \\
\text { pelaksanaan pengisian format tersebut } \\
\text { 2. Belum memuat rekomendasi intervensi yang } \\
\text { sudah dilakukan dan dilanjutkan di ruangan }\end{array}$ & $\begin{array}{l}\text { Format handover } \\
\text { kurang memuat SBAR }\end{array}$ \\
\hline
\end{tabular}

Penelitian (Bakon and Millichamp, 2017) menyimpulkan bahwa Handover Emergency dengan menggunakan form yang baru yaitu instrumen SBAR di ruang gawat darurat sesuai dengan standard akan lebih aman, dan dengan desain sangat baik akan lebih mudah untuk diterapkan sesuai standar klinik yang ada, proses handover juga dapat meningkatkan akuntabilitas dan tanggung jawab perawat. Hal tersebut memungkinkan perawat di ruang IGD RSU Haji untuk bekerja lebih aman karena mereka dapat mengisi isntrumen SBAR sesuai standar, apalagi keadaan di ruang IGD yang sibuk sehingga memerlukan efektifitas dan kecepatan waktu agar pasien dapat terselamatkan dari keadaan kegawatannya. Rasa aman yang dirasakan perawat karena sudah melaksanakan tugas pendokumentasian yang terstandar akan meningkatkan kepercayaan diri perawat dalam melaksanakan asuhan keperawatan pada pasien sehingga pasien mendapatkan perawatan yang optimal selama di ruang IGD RSU Haji Surabaya.

Perumusan isu strategis dari evaluasi dokumen SBAR di ruang IGD RSU Haji Surabaya dinilai menggunakan lembar observasi pada tabel 5.1. Indikator pertanyaan pada handover emergency dengan status present dari ruang IGD ke ruang rawat inap yang sedang dan sudah di terapkan di RSU Haji Surabaya, belum mengacu kepada Standar Nasional
Akreditasi Rumah Sakit. Pengisian lembar status present pada Handover Emergency juga belum sesuai standar karena belum terdapat SPO dan panduan pengisian yang jelas bagi perawat sehingga pelaksanaan komunikasi efektif SBAR pada Handover Emergency belum optimal.

Komunikasi yang efektif di kalangan profesional kesehatan adalah kunci untuk memastikan perawatan yang berkualitas dalam praktek klinis. Salah satu bentuk memastikan perawatan yang berkualitas dalam praktek klinis dalam bentuk komunikasi, handover klinis telah didefinisikan sebagai pengalihan tanggung jawab dan / atau akuntabilitas untuk perawatan pasien dari satu penyedia atau tim penyedia lain(Streeter, 2017)

Handover emergency sebagai sarana komunikasi antar profesi kesehatan dalam memberikan layanan terbaik dan dapat memberikan perawatan pada pasien secara tepat dan komprehensif bertujuan agar pasien mendapatkan terapi yang tepat sesuai keadaan sakitnya. Kondisi pasien di ruang IGD RSU Haji Surabaya yang mengalami kegawatan sehingga komunikasi keadaan pasien menjadi poin penting bagi perawat, dokter dan tenaga kesehatan lainnya untuk dapat memberikan perawatan yang tepat dan cepat. Komunikasi efektif SBAR pada handover emergency menjadi penting untuk 
menginformasikan fluktuasi kondisi pasien gawat darurat.

Instrumen SBAR di Ruang IGD mempunyai peranan penting dalam strategi pelayanan keperawatan. Penulisan Dokumen SBAR mempunyai format Problem Oriented, yaitu bersifat sederhana jelas, logis dan tertulis sesuai SNARS (2017), sehingga sangat perlu dokumen SBAR yang lengkap yang dapat menginformasikan kondisi pasien sampai dengan rekomendasi tindakan yang harus dilaksanakan sesuai keadaan sakit pasien untuk meningkatkan mutu pelayanan dan keselamatan pasien.

Setiap dokter atau dokter gigi dalam menjalankan praktik kedokteran wajib membuat rekam medik (Permenkes, 2008). Rekam medik harus dibuat segera dan dilengkapi setelah pasien menerima pelayanan. Pembuatan rekam medik dilaksanakan melalui pencatatan dan pendokumentasian hasil pemeriksaan, pengobatan, tindakan dan pelayanan lain yang telah dilaksanakan kepada pasien. Pencatatan yang lengkap termasuk pencatatan dalam format handover di IGD dapat menjadi poin penting dalam menginformasikan keadaan pasien saat transfer dari IGD dan dapat memberikan pertimbangan penting dalam menentukan terapi berikutnya untuk pasien.

Nursalam (2016) menjelaskan bahwa kapan saja perawat melihat pencatatan kesehatan, maka perawat dapat memberi dan menerima pendapat serta pemikiran. Pada kenyataanya, dengan semakin kompleksnya pelayanan keperawatan dan peningkatan kualitas keperawatan, perawat tidak hanya dituntut untuk meningkatkan mutu pelayanan tetapi dituntut untuk dapat mendokumentasikan secara benar. Keterampilan dokumentasi yang efektif memungkinkan perawat untuk mengkomunikasikan kepada tenaga kesehatan ainnya, dan menjelaskan apa yang sudah, sedang dan akan dikerjakan oleh perawat. Hasil penelitian menunjukkan bahwa kelengkapan dokumentasi komunikasi efektif SBAR saat di IGD pada item Assesment sekitar 9 yang terdokumentasi lengkap dan saat tranfer tidak ada sama sekali yang terdokumentasi. Gambaran hasil evaluasi DRM menunjukkan bahwa assesment hampir tidak terdokumentasi. Assesment dalam status present adalah hasil pemeriksaan fisik (kelainan yang ditemukan). Jika data pemeriksaan fisik tidak terdokumentasi dengan jelas maka data atau informasi tentang kondisi pasien tidak ada sehingga perawat di ruangan perlu melakukan pengkajian ulang terhadap kondisi psien terkini tan riwayat keadaan pasien saat mengalami kegawatan di IGD.

Uraian tersebut menunjukkan bahwa pada evaluasi status present belum optimal dan tidak sesuai standar dikarenakan pada dokumentasi status present belum menggambarkan kondisi dan perkembangan pasien yang sesuai dengan SNARS (2017) yaitu menggunakan format SBAR. Faktor yang menyebabkan ketidaklengkapan pengisian adalah belum adanya SPO (Standard Prosedur Operasional) dan petunjuk pengisian yang jelas, termasuk didalamnya item pengkajiannya belum sangat rinci menjelaskan keadaan pasien yaitu tentang Situation, Background, Assesment dan Recommendation.

Hambatan saat sosialisasi dan uji coba pengisian instrumen SBAR adalah waktu pengisian, karena ada beberapa pertanyaan dari perawat tentang mekanisme pengisiannya Sosialisasi dan uji coba dilaksanakan pada waktu yang sama sehingga waktu pelayanan di IGD pada saat uji coba menjadi lebih lambat. Thomson (2017) menggambarkan bahwa beberapa faktor berkontribusi pada kualitas handover emergency dan menjadi panduan dalam upaya untuk mengembangkan intervensi untuk meningkatkan kualitas serah terima shift antar perawat. Beberapa faktor penghambat pada saat uji coba instrumen SBAR misalnya waktu pendokumentasian dan jumlah pasien di IGD yang terus meningkat selanjutnya dapat dikondisikan perawat menjadi kegiatan yang harus 
dilaksanakan pada saat merawat pasien. Hasil akhir penelitian menunjukkan bahwa pelaksanaan proses sosialisasi dan uji coba berjalan lancar karena perawat dapat memahami dan melengkapi pengisian instrumen SBAR sesuai kondisi pasien di ruang IGD RS Haji Surabaya

\section{SIMPULAN}

Komunikasi efektif dari status present pada handover emergency di ruang IGD RSU Haji Surabaya belum memuat format SBAR (Situation, Background, Assesment, dan Recommendation).

\section{DAFTAR PUSTAKA}

Almas, S., Yegane, F., Shahrami, A., \& Hatamabadi, H. R. (2017). Clinical Information Transfer between EMS Staff and Emergency Medicine Assistants during Handover of Trauma Patients. (October), 1-7. https://doi.org/10.1017/S1049023X17 006562

Bakon, S., \& Millichamp, T. (2017). Optimising the emergency to ward handover process: A mixed methods study. Australasian Emergency Nursing Journal, 20(4), 147-152. https://doi.org/10.1016/j.aenj.2017.10 .001

Ballard, S. A., Peretti, M., Lungu, O., Voyer, P., Tabamo, F., Alfonso, L., ... Wilchesky, M. (2017). Factors affecting nursing staff use of a communication tool to reduce potentially preventable acute care transfers in long-term care. Geriatric Nursing, $1-5$. https://doi.org/10.1016/j.gerinurse.20 17.03.012

Campbell, D., \& Dontje, K. (2018). Implementing Bedside Handoff in the Emergency Department: A Practice Improvement Project. Journal of Emergency Nursing, 1-6. https://doi.org/10.1016/j.jen.2018.09. 007
Croos, S. (2014), a respite perspective. 23(13), 733-737.

Defenbaugh, N., \& Chikotas, N. E. (2016). Nurse Education in Practice The outcome of interprofessional education: Integrating communication studies into a standardized patient experience for advanced practice nursing students. Nurse Education in Practice, 16(1), 176-181.

https://doi.org/10.1016/j.nepr.2015.06 .003

Departemen kesehatan. (2017). Peraturan menteri kesehatan republik indonesia nomor 11 tahun 2017. Jakarta: departemen kesehatan.

Downey, L. V., Zun, L., \& Burke, T. (2013). What constitutes a good hand offs in the emergency department: A patient's perspective. International Journal of Health Care Quality Assurance, 26(8), 760-767. https://doi.org/10.1108/IJHCQA-032012-0028

Hidayat, A. A. (2014). Metodologi Penelitian Kebidanan \& Teknik Analisis Data Contoh Aplikasi Studi Kasus. Jakarta: Salemba Medika.

Kedokteran, K. (2006). Komunikasi Efektif Dokter-Pasien.

Kementerian Kesehatan. (2011). Peraturan Menteri Kesehatan Republik Indonesia nomor 1691/menkes/per/viii/2011.

Kerr, D., Klim, S., Kelly, A. M., \& Mccann, T. (2016). Impact of a modified nursing handover model for improving nursing care and documentation in the emergency department: A pre- and post-implementation study. International Journal of Nursing Practice, 22(1), 89-97. https://doi.org/10.1111/ijn.12365

Komisi Akreditasi Rumah Sakit. (2017). Standar Nasional Akreditasi Rumah Sakit Edisi 1.

Lyphout, C., Bergs, J., Stockman, W., Deschilder, K., Duchatelet, C., Desruelles, D., \& Bronselaer, K. 
(2017). Patient safety incidents during interhospital transport of patients: A prospective analysis. International Emergency Nursing, (July), 1-5. https://doi.org/10.1016/j.ienj.2017.07. 008

Moy, N. Y., Lee, S. J., Chan, T., Grovey, B., Boscardin, W. J., Gonzales, R., \& Pierluissi, E. (2014). Methods, tools, and strategies development and sustainability of an inpatient-tooutpatient discharge handoff tool: A quality improvement project. Joint Commission Journal on Quality and Patient Safety, 40(5), 219-227. https://doi.org/10.1016/S15537250(14)40029-1

Mundakir. (2016). Komunikasi Pelayanan Kesehatan. Yogyakarta: Indomedia Pustaka.

Nursalam. (2016). Manajemen Keperawatan (5th ed.; Lestari Peni Puji, Ed.). Jakarta: Salemba Medika.

Pawlikowska, T., Zhang, W., Griffiths, F., \& Dalen, J. Van. (2012). Patient Education and Counseling Verbal and non-verbal behavior of doctors and patients in primary care consultations - How this relates to patient enablement. Patient Education and Counseling, 86(1), 70-76. https://doi.org/10.1016/j.pec.2011.04. 019

Permenkes. (2017). KESELAMATAN PASIEN. 感染症誌, 91, 399-404.

Purnama Deni. (2016). Komunikasi, Informasi, dan Edukasi Efektif (Hanafi Irham, Ed.). Yogyakarta: Betha Grafika.

Rahman Fauzie. (2017). Komunikasi Kesehatan (Nugroho Adi, Ed.). Yogyakarta: Pustaka Panasea.

Streeter, A. R., \& Com-, A. (2017). Nurse Handoff Communication. Seminars in Oncology Nursing, 33(5), 536-543. https://doi.org/10.1016/j.soncn.2017.1 0.002

Watkins, L. M. (2014). Handoff Communication From the Emergency Department to Primary Care. 36(1), 44-51.

https://doi.org/10.1097/TME.0000000 000000003

Webster, D. (2014). Using Standardized Patients to Teach Therapeutic Communication in Psychiatric Nursing. Clinical Simulation in Nursing, 10(2), e81-e86. https://doi.org/10.1016/j.ecns.2013.08 .005 